\title{
Extra- and intracellular antimycobacterial activity of Arbutus unedo L.
}

\author{
Asmae El ouarti ${ }^{1}$, Amina Cherif Haouat ${ }^{1}$, Hakima Sqalli ${ }^{1}$, Abdellatif Haggoud ${ }^{1}$, \\ Abdeslam Ennabili ${ }^{2}$, Saad Ibnsouda ${ }^{1}$, Mohamed lachgar ${ }^{3}$ and Mohammed Iraqui ${ }^{1}$ \\ ${ }^{1}$ Laboratoire de Biotechnologie Microbienne, route d'Imouzzer, Faculté des Sciences et Techniques de Fès, Université \\ Sidi Mohammed Ben Abdellah, BP 2202, 30000 Fès, Maroc. \\ ${ }^{2}$ Institut National des Plantes Médicinales et Aromatiques, Université Sidi Mohammed Ben Abdellah, B.P. 159, 34015 \\ Taounate Principale, Maroc. \\ ${ }^{3}$ Faculté des Sciences Dhar EL Mehrez, B.P. 1796 Fès-Atlas, 30003 Maroc.
}

Accepted 17 January, 2012

\begin{abstract}
This study aims to evaluate extra- and intracellullar antimycobacterial activity of Arbutus unedo L. leaves-extracts. We tested the aqueous and ethanol extracts of Arbutus leaves effect against three mycobacteria growth, and showed that aqueous extract and the part I of ethanol extract have a remarkable extracellular antimycobacterial activity. The MIC (Minimum inhibitory concentration) of the part I of ethanol extract is $5.59 \pm 0.69 \mathrm{mg} / \mathrm{ml}$ for Mycobacterium aurum A + and $6.02 \pm 0.76 \mathrm{mg} / \mathrm{ml}$ for Mycobacterium smegmatis $\mathrm{MC}_{2}$ and Mycobacterium bovis PPI. The part I of arbutus ethanol-extract, used at $6.02 \pm 0.76 \mathrm{mg} / \mathrm{ml}$, has a bactericidal effect on $M$. smegmatis $M_{2} C_{2}$ located within the rat peritoneal macrophages.
\end{abstract}

Key words: Antimycobacterial activity, Arbutus unedo L., rat peritoneal macrophages.

\section{INTRODUCTION}

The infectious disease tuberculosis is engendered by several species of Mycobacteria (Asgharzadeh and Kafil, 2007) including Mycobacterium tuberculosis, Mycobacterium bovis, Mycobacterium africanum, Mycobacterium microti, Mycobacterium avium and Mycobacterium leprae that are intracellular, Grampositive, non-motile, rod-shaped, and obligate aerobic pathogens of higher vertebrates (Chakraborty, 2004).

Pathogenic mycobacteria agents are particularly ingenious, as they are able to survive, and even replicate within macrophages that are designed specifically to kill bacteria. They are exceptional in the duration and persistence of this interaction, seeing that the mycobacterial phagosome does not fuse with lysosomes (Armstrong and Hart, 1975; Frehel et al., 1986; Hart and Young, 1991). Latent infection as a main obstacle to controlling tuberculosis results from the survival of $M$.

\footnotetext{
*Corresponding author. E-mail: mhiraqui@yahoo.fr.
}

teburculosis in macrophage (Houben et al., 2006; Zahrt, 2003).

In addition to HIV-infection spreading, tuberculosis progress especially in countries with insuitable health care-systems providing an expensive and long-term treatment (World Health Organisation, 2008; Zager and McNerney, 2008). The emergence of multiple drug resistant (MDR) strains is a further crisis, including extremely drug resistant (XDR) $M$. tuberculosis-strains (Jones et al., 2008).

Even though the number of tuberculosis-related deaths appears to have stabilized at about 2 million per annum, the incidence of new infections increase largely because of HIV epidemic (Gutierrez-Lugo and Bewley, 2008). There would be many challenges to eradicate tuberculosis, including latency and drug resistance (Gutierrez-Lugo and Bewley, 2008). New purposes for novel anti-tuberculosis drugs need to be identified, as emergent MDR and XDR $M$. tuberculosis-strains. Although the complete genome sequences of $M$. tuberculosis H37Rv (Cole, 1998) and two other members 
of the M. tuberculosis complex (Cole, 2002) are available, it is likely to be many years before exploitation of this information yields novel therapeutics (Cole, 2002).

Plants and other natural materials may prove to be valuable sources of useful new antimycobacterial drugs. A number of studies have revealed the existence of a range of natural products with promising activity against mycobacteria (Newton, 2000; Cantrell, 2001).

Strawberry tree, Arbutus unedo L. (Ericaceae), is a typical species of Mediterranean fringe and climate, but today it is also cultivated in many other regions such as the near East and Transcaucasia (Seidemann, 1995). Previous studies indicate that leaves of Arbutus unedo contain several phenolic compounds like tannins, flavonoids, phenolic glycosides, lipids and vitamin $E$ (Chevolleau et al., 1992; Fiorentino et al., 2007; Kıvçak and Mert, 2001; Pabuçcuoğlu et al., 2003). This melliferous plant has a medicinal properties, namely the leaves and bark (Rocha-Afonso, 1991). In the Oriental Morocco, the leaves are frequently used in the traditional medicine system as a natural remedy for hypertension and diabetes (Ziyyat et al., 1997). Beside this effect, other properties were reported in the literature. Experimental investigations have shown that the ethanol and methanol extracts of Arbutus unedo-leaves present a potent antioxidant activity (Pabuçcuoğlu et al., 2003). The ethanol extract can also be a promising antileishmanial agent (Kivçak et al., 2009), and the ethyl acetate extract of strawberry leaves show an anti-trichomonacidal effect (Ertabaklar et al., 2009). Moreover, the aqueous extract of the plant exhibited antihypertensive and vasorelaxant activities, and they inhibited in vitro rat platelet aggregation (Mekhfi et al., 2006; Ziyyat et al. 2002; Ziyyat and Boussairi, 1998).

In the present study, we are investigated an extra- and intracellular amtimycobacterial activities of Arbutus unedo-leaves extracts.

\section{MATERIALS AND METHODS}

\section{Plant material}

Arbutus unedo leaves were collected in October, 2009 from the Imouzzar Kandar surrounding-area $\left(33^{\circ} 43^{\prime} 40^{\prime \prime} \mathrm{N}-5^{\circ} 0^{\prime} 43^{\prime \prime} \mathrm{W}\right)$.

Specimens of this species are gathered in the National Institute of Medicinal and Aromatic Plants, Sidi Mohamed Ben Abdellah University, Fez (exsiccata INP789).

The leaves were dried in the open air shade. They were then stored in paper bags, at a room temperature and kept away from humidity till the date of extraction.

\section{Antimycobacterial strains and growth conditions}

Three non-pathogenic mycobacterial strains were used during this study. Two fast growing species are $M$. aurum $A+$ and $M$. smegmatis $\mathrm{MC}_{2}$ and one slow growing is $M$. bovis PPI". This strain is used as a model to evaluate the effect of active substances on the growth of $M$. tuberculosis (Newton et al., 2000, 2002). M. smegmatis and $M$. aurum have been shown to have similar profile of sensitivity to anti-tuberculosis drugs (Chung et al., 1995; Mitscher and Baker, 1998). $M$. bovis is more closely resembled to $M$. tuberculosis than $M$. aurum and $M$. smegmatis seeing that $M$. tuberculosis and $M$. bovis are both slow growing organisms (Newton et al., 2002).

These bacteria are cultivated at $37^{\circ} \mathrm{C}$ on Sauton medium (Allen 1998; Papa et al., 1987). The mycobacteria were kindly provided by Dr. Suzana David Dr. S. David (Centro de Tuberculose e Micobactérias, Instituto Nacional de Saúde Dr.Ricardo Jorge Delegação do Porto, Portugal).

\section{Preparation of plant extracts}

(i) Aqueous extract: dried and powdered leaves from Arbutus unedo (15 g) were plunged in ebullient water during $1 \mathrm{~h}$ (infused) or in ebullient water and heated during 15 and $30 \mathrm{~min}$ (decocted). The extracts were then filtered.

(ii) Ethanol extract: dried and powdered leaves from Arbutus unedo (15 g) were extracted by maceration in $50 \mathrm{ml}$ of ethanol during $24 \mathrm{~h}$. This extract was then filtered and the organic solvent evaporated using a rotary-evaporator at $40^{\circ} \mathrm{C}$ to yield $1035.3 \pm 94.2 \mathrm{mg}$ of crude extract. The residue obtained was prepared by first dissolving in (DMSO) (Newton et al., 2002) and diluting with a liquid Sauton medium or RPMI-1640 culture medium of macrophages and then further filtered. $598.5 \pm 73.9 \mathrm{mg}$ of crude extract are soluble in medium culture (part I) and $436.8 \pm 26.2 \mathrm{mg}$ not soluble in the medium culture filter results (part II). The volume of liquid medium added was differed according to a concentration of extract desired. The DMSO ratio should be inferior or equal $2 \%$. Control experiments showed that a final concentration of DMSO (2\%) did not affect the growth of antimycobacterial strains used. The extracts were neutralized and sterilized by filtration through a $0.45 \mu \mathrm{m}$ membrane filter.

\section{Extracellular antimycobacterial activities of aqueous and ethanol plant extracts}

The test of the extracellular antimycobacterial activity was realized by the extracts incorporation in the culture medium according to the agar diffusion and agar dilution and broth dilution assays.

(i) Agar dilution assay: aqueous and ethanol extract (part I) are added in the culture medium Sauton-agar (Allen, 1998; Papa et al., 1987 ) to reach a final concentration of $160 \mathrm{mg}$ of dry matter per $\mathrm{ml}$ of medium. This concentration is relatively elevated. Indeed, using a less concentration could hide the antimycobacterial effect of plant extracts of which the active principle is present in very faint quantity. Besides, several anterior investigations have used concentrations that are superior or equal to $100 \mathrm{mg} / \mathrm{ml}$ in dry matter (Ahmad and Beg, 2001; Cos et al., 2002; Olila et al., 2001). Aliquots of $100 \mu \mathrm{l}$ of mycobacterial cultures of $M$. smegmatis $\mathrm{MC}_{2}$ and $M$. aurum $\mathrm{A}+$ and M. bovis IPP $\left(10^{6} \mathrm{UFC} / \mathrm{ml}\right)$ were then spread over the medium thus prepared and incubated at $37^{\circ} \mathrm{C}$. The results are read every day during 6 days for rapidly growing mycobacteria and after 21 to 30 days of incubation for $M$. bovis PPI. This test was repeated 4 times, for each mycobacterial species. The control used corresponded to the Sauton-agar medium without of Arbutus extracts. The ethanol extract part II does not dissolves in the liquid culture medium sauton and thus part of ethanol extract does not test by Agar dilution assay.

(ii) Agar diffusion assay: the extracellular antimycobacterial activity of ethanol extract part I and part II was also tested by method of discs (Bauer et al., 1966). Sterilized discs of Whatman paper (diameter: $6 \mathrm{~mm}$ ) were deposited on agar culture medium beforehand inoculated independently by $100 \mu \mathrm{l}$ of each mycobacterial culture (approximately $10^{6} \mathrm{UFC} / \mathrm{ml}$ ). The discs were deposited on 6 Petri dishes (1 disc per Petri dishes). Three discs were then impregnated with ethanol extract part I and deposed at a 
dose of $160 \mathrm{mg}$ of dry matter per disc on 3 other discs ethanol extract part II dried. This dose of dry matter give $6.38 \mathrm{mg}$ of ethanolic extract residue part I, and $4.66 \mathrm{mg}$ of ethanolic extract residue part II. The ethanol extracts residues were prepared like describe above. The Petri prepared dishes were incubated at $37^{\circ} \mathrm{C}$ during 3 to 4 days for rapidly growing mycobacteria and after 21 to 30 days of incubation for $M$. bovis PPI. The control used corresponded to discs impregnated with a liquid medium.

(iii) Broth dilution assay: The MIC determination of ethanol extract part I for the mycobacterial species was realized according to the broth dilution method as described by Rastogi et al. (1991). Tubes containing $6 \mathrm{ml}$ of sauton liquid medium alone (control) or supplemented with increasing concentrations of ethanol extract part I, from 0.24 to $6.38 \mathrm{mg} / \mathrm{ml}$, were inoculated with a freshly grown culture to give an $\mathrm{OD}_{595}$ about of 0.3 for $M$. bovis PPI, and 0.2 for $M$. smegmatis $\mathrm{MC2}$ and $M$. aurum $A+$. The tubes were then incubated with agitation at $37^{\circ} \mathrm{C}$ during 3 days for rapidly growing mycobacteria and 5 days for M. bovis PPI (Billo et al., 2005; Eldeen and Van Staden, 2008; Newton et al., 2002). The growth of control tubes has reached a $D_{595}$ of 0.4 for $M$. bovis and $M$. aurum $A+$, and of 0.9 for $M$. smegmatis $M_{2}$. The MIC was determined as the minimum concentration of extract for which resulted in no visible growth in tubes (the initial absorbance of cultures has not changed). A glass marble in each tube and an agitation before the measure of the OD was necessary to avoid clumping of bacilli. This experiment was repeated four times in separate days.

\section{Intracellular antimycobacterial activity of ethanol plant extract} part I

The extracellular antimycobacterial activity of ethanol plant extract part I was tested against $M$. smegmatis inside the mice peritoneal macrophages according to the following stapes:

(i) Isolation of peritoneal rat macrophages: Peritoneal macrophage isolation was performed relying on Morissette et al. (1996) and Sosunov et al. (2007) works. Rat was injected intraperitoneally with cold Hanks balanced salt solution containing kanamicyn $(60 \mu \mathrm{g} / \mathrm{ml})$. After $10 \mathrm{~min}$, a short abdominal incision is made and the cell suspension is collected by suction to the syringe. Cells were washed twice, re-suspended in RPMI-1640 cell culture medium and $5 \times 10^{5}$ cells/well were allowed to adhere to the bottom of 96 -well tissue culture plate following an incubation period of $2 \mathrm{~h}$ at $37^{\circ} \mathrm{C}$ and $5 \% \mathrm{CO}_{2}$. The cellular density of viable macrophages was determined by Trypan Blue exclusion (Denis et al., 1990).

(ii) Infection of macrophages by bacilli: The adhered macrophages in each well of the tissue culture plate were inoculated with about 7 $\times 10^{5}$ bacilli of $M$. smegmatis MC2. For this purpose, the medium from each well was replaced with another fresh medium containing the required bacterial concentration. Phagocytosis was allowed for $4 \mathrm{~h}$ at $37^{\circ} \mathrm{C}$ and $5 \% \mathrm{CO}_{2}$ (Rastogi et al., 1987). After phagocytosis, the medium from each well was retired and the cells were then treated during $1 \mathrm{~h}$ by a medium containing $10 \mu \mathrm{g} / \mathrm{ml}$ of amikacin. This treatment was followed by several changes of hanks balanced salt solution to remove all extracellular M. smegmatis MC2 (Rastogi et al., 1987, 1991; Sharbati-Tehrani et al., 2005).

(iii) Treatment by plant ethanol extract: About $5 \mathrm{~h}$ after infection, necessary time of phagocytosis and elimination of extracellular $M$. smegmatis MC2, the ethanol leaves plant extract $(6.02 \pm 0.76$ $\mathrm{mg} / \mathrm{ml}$ ) which was solubilized in RPMI-1640 as demonstrated above, was added to the wells containing infected macrophages. The tissue culture plate like this prepared was then incubated at $37^{\circ} \mathrm{C}$ and $5 \% \mathrm{CO}_{2}$.

(iv) Enumeration of phagocytosed bacilli: After 4, 24, 48 and $72 \mathrm{~h}$ of treatment, the infected macrophages were lysed by adding $0.25 \%$ $(w / v)$ sodium dodecyl sulfate (SDS), followed by a quick shaking and then the lysates were immediately removed from each well of tissue culture plate and centrifuged. After that, SDS was eliminated; bacilli were re-suspended in Sauton medium and then were plated on the Sauton agar medium. The colony-forming units (CFU) were enumerated after about 4 days of the Petri dishes incubation at $37^{\circ} \mathrm{C}$. As described by Rastogi et al. (1991), this treatment with $0.25 \%(w / v)$ SDS did not affect the viability of mycobacteria. The results were compared with the growth of the bacilli in the control culture (untreated macrophages). Results are means of 3 experiments.

(v) Cytotoxicity assay: The cytotoxicity of the peritoneal macrophages treated with the ethanol extract part I was measured by the neutral red uptake assay after 3 days of incubation (Lindl and Bauer, 1989). Only living cells are able to manage the active uptake of neutral red (Borenfreund and Puerner, 1984.). Following 3 days exposure to the ethanol arbutus extract part I (6.02 \pm 0.76 $\mathrm{mg} / \mathrm{ml}$ ), the peritoneal macrophages that stuck to the tissue culture plate were washed with Hanks and incubated for $2 \mathrm{~h}$ with neutral red dye $(100 \mu \mathrm{g} / \mathrm{ml})$ dissolved in RPMI-1640 medium. Cells were washed again with Hanks to remove all extracellular Neutral red (Fotakis and Timbrell, 2006). The addition 10\% acetic acid plus $40 \%$ ethanol solution followed by gentle shaking allowed extraction the dye from the cells in addition to its solubilization. The absorbance was read at $550 \mathrm{~nm}$ (Bonatto et al., 2004). The Results are compared with those of control cultures: The rat peritoneal macrophages incubated in RPMI-1640 cell culture medium and those treated with $0.25 \%$ SDS as a cytotoxic solution. The results are also means of 3 experiments.

\section{Statistical analysis}

Results were expressed as Mean \pm SEM. The comparison between control and the Tread samples was analyzed using Stutent's t-test and $p<0.05$ was considered to be significant.

\section{RESULTS AND DISCUSSION}

\section{Extracellular antimycobacterial activities of aqueous and ethanol plant extracts}

The aqueous and ethanol arbutus leaves extracts part I, which follow the experimental protocol described previously, which showed a remarkable extracellular antimycobacterial activity. Indeed, the culture meduim agar incorporated infusion and decoction, and ethanol plant extract part I inhibited complete growth of mycobacterial strains tested (Table 1). So we can suppose those extracts able to inhibit the proliferation of mycobacteria through one or more active substance(s). The decoction of the antimycobacterial activity observed for 15 and 30 min after decoction showed that the active ingredient responsible was not altered by heating to $100^{\circ} \mathrm{C}$ (Table 1). This means that the active ingredient soluble in water and ethanol is probably not such a peptid or protein. The $\mathrm{pH}$ of the extracts tested were adjusted to near 7 , witch prove that the inhibition is due to the plant extracts studied and not to $\mathrm{pH}$.

The antimycobacterial activity of the Arbutus unedo ethanol-extract part $\mathrm{I}$ is also manifested by the appearance of a large inhibition zones around the discs of Whatman paper impregnated with this extract (Table 2). These zones correspond to the inhibition of the 
Table 1. Antimycobacterial effect of Arbutus unedo extracts.

\begin{tabular}{lccccc}
\hline & \multicolumn{4}{c}{ Antimycobacterial effect of severel extracts } & \multirow{2}{*}{ Control } \\
\cline { 2 - 5 } \cline { 4 - 5 } Mycobacteria & \multirow{2}{*}{ Ethanolic extract part I } & Infused & $\mathbf{1 5}$ min & $\mathbf{3 0 ~ m i n}$ & \\
\hline$M$. smegmatis $\mathrm{MC}_{2}$ & - & - & - & - & + \\
M. aurum A+ & - & - & - & - & + \\
M. bovis PPI & - & - & - & - & + \\
\hline
\end{tabular}

: Total inhibition of growth. + : Growth. The Control correspond to the cultures without extracts.

Table 2. Antimycobacterial activity of Arbutus unedo ethanlic extract.

\begin{tabular}{|c|c|c|c|}
\hline Mycobacteria & $\begin{array}{c}\text { Diameter of inhibition zone }(\mathrm{mm}) \\
\text { of ethanolic extract part I }\end{array}$ & $\begin{array}{c}\text { Diameter of inhibition zone }{ }^{2}(\mathrm{~mm}) \\
\text { of ethanolic extract part II }\end{array}$ & CMI (mg/ml) \\
\hline M. & $33.7 \pm 1.86$ & 0 & .76 \\
\hline um $A+$ & $34.3 \pm 0.67$ & 0 & $5.59 \pm 0.69$ \\
\hline M. bovis PPI & $34.7 \pm 1.76$ & 0 & $6.02 \pm 0.76$ \\
\hline
\end{tabular}

${ }^{1}$ The dose is $6.38 \mathrm{mg}$ of residue / disc, corresponding to $160 \mathrm{mg}$ of dry matter / disc. ${ }^{2}$ The dose is $4.66 \mathrm{mg}$ of residue/ disc, corresponding to $160 \mathrm{mg}$ of dry matter / disc.

bacterial growth, following the agar diffusion of the active metabolite produced. On the contrary, no zone of inhibition has been appeared around the deposit of the ethanolic extract part II. This part of the extract, used in a dry state, showed no antimycobacterial activity against the three strains tested, although it diffuses into the sauton culture medium agar.

The ethanol extract part I dose was used in this study is $6.38 \mathrm{mg}$, corresponding to $160 \mathrm{mg}$ of dry matter. However, the activity detected at the same dose was similar in comparison with the obtained one against the three mycobacterial strains tested (M. smegmatis and $M$. aurum $\mathrm{A}+$ and $M$. bovis PPI). There is no significant difference between the diameters of inhibitin zones of those mycobacteria $(p>0.05)$. These strains have the same sensitivity to the ethanolic extract part I. Dulger and Gonuz (2004) have also tested the antimycobacterial effect of ethanol extracts of 16 plants against $M$. smegmatis by the agar diffusion assay and they observe inhibition of growth by 9 species: Nigella sativa, Lythrum salicaria, Pistacia terebinthus, Malva sylvestris, Myrtus communis, Origanum vulgare, Rosmarinus officinalis, Tanacetum vulgare and Tussilago farfara. The zones of inhibition of extracts from these plants are lower than those obtained in this study, despite a higher dose of extract, which underscores the importance of the antimycobacterial effect in vitro of ethanol extract part I of Arbutus unedo leaves.

After having revealed the inhibitory activity of Arbutus unedo leaves ethanol extract part I by previous methods, MICs for the mycobacterial species studied are then determined. The MIC was $5.59 \pm 0.69 \mathrm{mg} / \mathrm{ml}$ for $M$. aurum $\mathrm{A}+$ and $6.02 \pm 0.76 \mathrm{mg} / \mathrm{ml}$ for $M$. smegmatis MC2 and $M$. bovis PPI (Table 2). Confirming the results obtained with the method of discs, the MIC study showed that the ethanol extract part I has approximately the same inhibitory effect against growth of the three bacterial species tested: $M$. smegmatis, $M$. aurum $\mathrm{A}+$ and $M$. bovis PPI $(p>0.05)$. These results confirmed the results obtained with the method of discs.

\section{Intracellular antimycobacterial activity of ethanolic plant extract part I}

Pathogenic mycobacterial strains are intracellular parasites. Therefore, an amtimycobacterial agent must be active inside cells (Draper, 1981; Mangalindan et al., 2000; Skinner et al., 1995). To visualize the intracellular Antimycobacterial activity of Arbutus unedo leaves ethanolic extract part I, we followed the $M$. smegmatis $\mathrm{MC}_{2}$ growth inside rat peritoneal macrophages treated and untreated with the extract. For this way we enumerated bacillis witch were phagocytosed by the peritoneal macrophages. This enumeration consists of bacterial counts containing in the lysis solution spread on the medium culture Sauton agar.

Five hours after phagocytosis of $M$. smegmatis and the elimination of extracellular bacteria, phagocytes infected untreated and treated with ethanol extract part I were reincubated. This time point is referred to as 0 hof postinfection. Figure 1 shows that after $4 \mathrm{~h}$ of post infection, the UFC of $M$. smegmatis $M_{2}$ phagocytosed by macrophages untreated, changed from $1500 \pm 50$ to 1312 $\pm 141 \mathrm{UFC} /$ well. This showed that the strain persist within phagocytes during the initial hours of post-infection. 


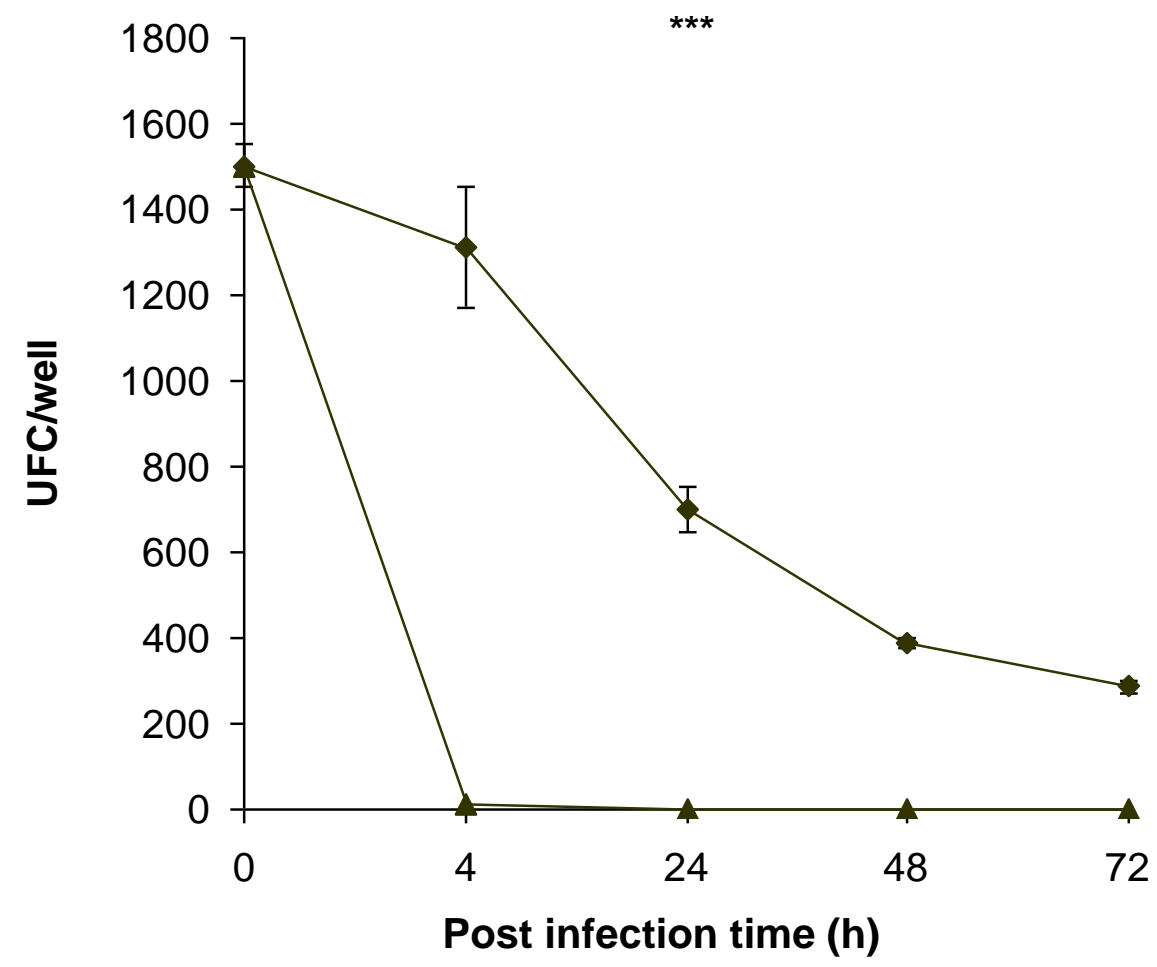

Figure 1. Antimycobacterial effect of Arbutus unedo ethanolic extract against $M$. smegmatis $\mathrm{MC}_{2}$ infecting rats peritoneal macrophages. number of intracellular surviving strains of $M$. smegmatis $\mathrm{MC}_{2}$, enumerated in the lysate of rat peritoneal macrophages inoculated with the mycobacteria and untreated with the extract $\boldsymbol{\Delta}$ : number of intracellular surviving strains of $M$. smegmatis $\mathrm{MC}_{2}$ enumerated in the lysate of rat peritoneal macrophages inoculated with mycobacteria and treated with the extract. Repetitions number $(\mathrm{n})$ between 6 and $10,{ }^{* *} \mathrm{p}<0.001 .5 \mathrm{~h}$ after phagocytosis of $M$. smegmatis $\mathrm{MC}_{2}$ and the elimination of extracellular bacteria is referred as $0 \mathrm{~h}$ of postinfection.

Afterward, this value is gradually decreasing with the incubation period and reached $701 \pm 52$ UFC/well after $24 \mathrm{~h}, 387 \pm 11 \mathrm{UFC} /$ well after $48 \mathrm{~h}$ and finally $287 \pm$ $14 \mathrm{UFC} /$ well after $72 \mathrm{~h}$. These results showed that $M$. smegmatis is unable to multiply inside macrophages, as reported in several previous works (Douglas et al., 2004; Sharbati-Tehrani et al., 2005). For the macrophages treated with the extract (Figure 1), we observed a significant decrease in the number of mycobacteria compared with mycobacterial load in untreated rat peritoneal macrophages. Indeed, after 4 hof post-infection, the UFC of bacilli in macrophages treated decrease imediatly to $1500 \pm 50 \mathrm{UFC} /$ well and reach $12 \pm 1 \mathrm{UFC} /$ well $(p<$ 0.001 ), and then $0 \mathrm{UFC} /$ well after $24 \mathrm{~h}$ of post- infection $(p<0.001)$. It appears that the Arbutus unedo ethanolic extract part I, used at $6.02 \pm 0.76 \mathrm{mg} / \mathrm{ml}$, showed potent intracellular antimycobacterial activity against $M$. smegmatis $\mathrm{MC}_{2}$. The extract has inactivated the majority of phagocytosed bacilli after $4 \mathrm{~h}$ of treatment and all intracellular bacilli after $24 \mathrm{~h}$ of treatment. This allowed us to conclude that the active plant constutient has a bactericidal effect on the mycobacteria located within the rat peritoneal macrophages. As $M$. smegmatis and $M$. tuberculosis have the same sensitivity to anti-tuberculose drugs (Mitscher and Baker, 1998), we suggest that the extract of this plant would have an inhibiting effect on $M$. tuberculosis infected macrophages.

Previous phytochemical studies of Arbutus unedo indicate that leaves contain several phenolic compounds like tannins, flavonoids, phenolic glycosides, etc.. The strawberry leaves also contain lipids and vitamin $E$ (Chevolleau et al., 1992; Fiorentino et al., 2007; Kıvçak and Mert, 2001; Pabuçcuoğlu et al., 2003).

The antimycobacterial activity of this plant could be attributed to phenolic compounds. Accordingly, several studies have shown that the phenolic compounds isolated from a number of plant extracts have significant antimycobacterial activity (Koysomboon et al., 2006; Mativandlela et al., 2008; Okunade et al., 2004). However, it is not excluded that other classes of fractions would be also implied. Further experiments are needed for isolation of active fractions and identification of the active components of ethanol extract.

The study of the cytotoxicity of rat peritoneal macrophages treated with the extract is performed by testing their ability to uptake neutral red. Figure 2 shows 


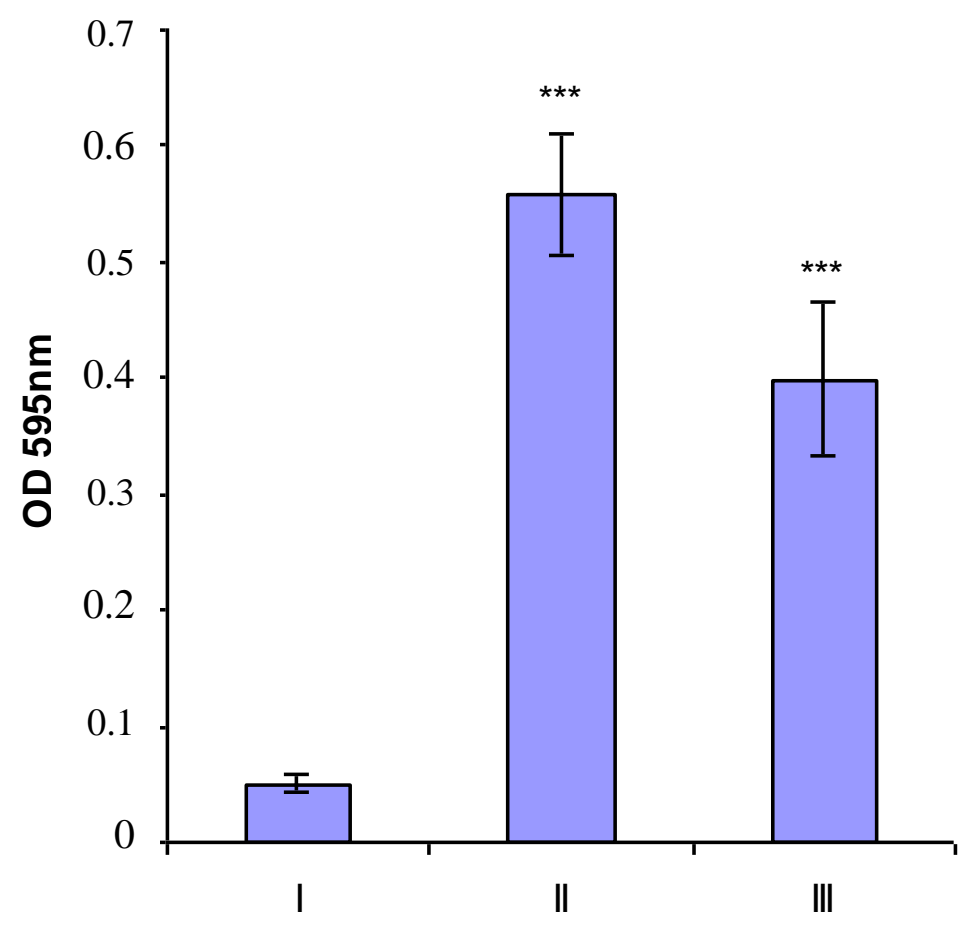

Figure 2. Cytotoxicity of Arbutus unedo leaves ethanol extract (part I). I: OD 595 of the neutral red dye uptake by rat peritoneal macrophages treated with $0.25 \%$ SDS (repetitions nombre $(n)=8$ ); II: OD 595 of the dye uptake by rat peritoneal macrophages treated 3 days by ethanol extract part I $(n=6)$; III: OD 595 of the dye uptake by rat peritoneal macrophages incubated in RPMI -1640 cell culture meduim $(n=7) .{ }^{* * *} p$ $<0.001$ compared with mycobacterial load in rat peritoneal macrophages treated with $0.25 \%$ SDS.

that there is no significant difference between the concentration of neutral red incorporated by peritoneal macrophages treated with the Arbutus unedo leaves ethanol extract part I (OD $595=0.5 \pm 0.05)$ and untreatated macrophages [macrophages incubated with RPMI-1640 cell culuntre medium (OD $595=0.4 \pm 0.06$ )] $p>0.05$. Whereas, the concentration of neutral red uptaked by macrophages treated with the cytotoxic solution of SDS is significantly lower $(\mathrm{OD}=0.05 \pm$ $0.008)^{* * *} p<0.001$. We find that the peritoneal macrophages treated with the extract are able to uptake the red neutral dye after 3 days of treatement. This showed that the extract used at $6.02 \pm 0.76 \mathrm{mg} / \mathrm{ml}$ had no toxic effect.

\section{Conclusion}

The water extract and soluble ethanol extract of Arbutus unedo leaves can be a promising amtimycobacteral agent in the future, especially because the ethanolic extract part I shows an intracellular antimycobacterial activity and has no toxic effect on macrophages. This amtimycobacteral activity could be attributed to a number of phytochemical compounds present in the aqueous and ehanolic extracts such as phenols.

\section{REFERENCES}

Ahmad I, Beg AZ (2001). Antimicrobial and phytochemical studies on 45 Indian medicinal plants against multi-drug resistant human pathogens. J. Ethnopharmacol., 74(2): 113-123.

Allen BW (1998). Mycobacteria: general culture methodology and safety considerations. In: Parish T, Stoker N (Eds) Mycobacteria protocols, Humana Press, Totowa, N.J., pp. 15-30.

Armstrong JA, Hart PD (1975). Phagosome-lysosome interactions in cultured macrophages infected with virulent tubercle bacilli. Reversal of the usual nonfusion pattern and observations on bacterial survival. J. Exp. Med., 142: 1-16.

Asgharzadeh M, Kafil HS (2007). Current trends in molecular epidemiology studies of $M$. tuberculosis. Biotechnol. Mol. Biol. Rev., 2: $108-115$

Bauer AW, Kirby WMM, Sherris JC, Turck M (1966). Antibiotic susceptibility testing by standardized single disk method. Am. J. Clin. Pathol., 45(4): 493-496.

Billo M, Cabalion P, Waikedre J, Fourneau C, Bouttier S, Hocquemiller $R$, Fournet A (2005). Screening of some new Caledonian and Vanuatu medicinal plants for antimycobacterial activity. J. Ethnopharmacol., 96(1-2): 195-200.

Bonatto SJR, Folador A, Aikawa J, Yamazaki RK, Pizatto N, Oliveira $\mathrm{HH}$, Vecchi R, Curi R, Calder PC, Fernandes LC (2004). Lifelong exposure to dietary fish oil alters macrophage responses in Walker 256 tumor-bearing rats. Cell Immunol., 231(1-2): 56-62.

Borenfreund E, Puerner JA (1984). A simple quantitative procedure using monolayer culture for toxicity assays. J. Tissue Cult. Meth. 9: 7-9.

Cantrell CL, Franzblau SG, Fischer NH (2001). Antimycobacterial plant 
terpenoids. Planta Med., 67: 685-94.

Chakraborty AK (2004). Epidemiology of tuberculosis; Current status in India. Indian J. Med Res., 120: 248-76.

Chevolleau S, Georges C, Demande Fr (1992). Extraction of D- $\mu$ tocopherol from plant leaves. Patent No: FR 2669032. D

Chung GA, Aktar Z, Jackson S, Duncan K (1995). Highthroughput screen for detecting antimycobacterial agents. Antimicrob Agents Chemother, 39: 2235-2238.

Cole ST, Brosch R, Parkhil J, GarnieT, Churche C, Harris D (1998). Deciphering the biology of Mycobacterium tuberculosis from the complete genome sequence. Nature, 393: 537-544.

Cole ST (2002). Comparative mycobacterial genomics as a tool for drug target and antigen discovery. Eur. Respir. J., 36: 78s-86s.

Cos P, Hermans N, De Bruyne T, Apers S, Sindambiwe JB, Vanden Berghe D, Pieters L, Vlietinck AJ (2002). Further evaluation of Rwandan medicinal plant extracts for their antimicrobial and antiviral activities. J. Ethnopharmacol., 79(2): 155-163.

Denis M, Forget A, Pelletier M, Gervais F, Skamene E (1990). Killing of Mycobacterium smegmatis by macrophages from genetically susceptible and resistant mice. J. Leukoc. Biol., 47(1): 25-30.

Douglas T, Daniel DS, Parida BK, Jagannath C, Dhandayuthapani S (2004). Methionine sulfoxide reductase A (MsrA) deficiency affects the survival of Mycobacterium smegmatis within macrophages. J. Bacteriol., 186(11): 3590-3598.

Draper $P$ (1981). Mycobacterial inhibition of intacellular killing. In O'Grady F, Smith H (Eds.) Microbial perturbation of host defenses. London: The Beecham Colloquia, Academic Press, pp. 143-164.

Dulger B, Gonuz A (2004). Antimicrobial activity of certain plants used in Turkish traditional medicine. Asian J. Plants Sci., 3(1): 104-107.

Eldeen IMS, Van Staden J (2008). Anti-inflammatory and mycobacterial activity of leaf extracts of Coleonema album. South Afr. J. Bot., 74(2): 345-347.

Ertabaklar H, Kivçak B, Mert T, Özensoy Töz S (2009). In vitro Activity of Arbutus unedo Leaf Extracts against Trichomonas vaginalis Trophozoites. Türkiye Parazitol Derg. 33(4): 263-265.

Fiorentino A, Castaldi S, D'Abrosca B, Natale A, Carfora A, Messere A, Monaco P (2007). Polyphenols from the hydroalcoholic extract of Arbutus unedo living in a monospecific Mediterranean woodland. Biochem. Syst. Ecol., 35: 809-811.

Fotakis G, Timbrell JA (2006). In vitro cytotoxicity assays: Comparison of LDH, neutral red, MTT and protein assay in hepatoma cell lines following exposure to cadmium chloride. Toxicol. Lett., 160(2): 171177.

Frehel C, de Chastellier C, Lang T, Rastogi N (1986). Evidence for inhibition of fusion of lysosomal and prelysosomal compartments with phagosomes in macrophages infected with pathogenic Mycobacterium avium. Infect. Immun., 52: 252-262.

Gutierrez-Lugo MT, Bewley CA (2008). Natural products, small molecules, and genetics in tuberculosis drug development. J. Med. Chem., 51: 2606-2612.

Hart PD, Young MR (1991). Ammonium chloride, an inhibitor of phagosome-lysosome fusion in macrophages, concurrently induces phagosome-endosome fusion, and opens a novel pathway: studies of a pathogenic mycobacterium and a non-pathogenic yeast. J. Exp. Med., 174: 881-889.

Houben EN, Nguyen L, Pieters J (2006). Interaction of pathogenic mycobacteria with the host immune system. Curr. Opin. Microbiol., 9: 76-85.

Jones KDJ, Hesketh T, Yudkin J (2008). Extensively drug-resistant tuberculosis in sub-Saharan Africa: an emerging public-health concern. Trans. R. Soc. Trop. Med. Hyg. 102: 219-224.

Kıvçak B, Mert T (2001). Quantitative determination of a-tocopherol in Arbutus unedo by TLC-densitometry and colorimetry. Fitoterapia. 72: 656-661.

Kivçak B, Mert T, Ertabaklar H, Balcioglu IC, Özensoy Töz S (2009). In vitro Activity of Arbutus unedo Against Leishmania tropica Promastigotes. Türkiye Parazitol Derg., 33(2): 114 -115.

Koysomboon S, Van Altena I, Kato S, Chantrapromma K (2006). Antimycobacterial flavonoids from Derris indica. Phytochemistry, 67: 1034-1040.

Lindl T, Bauer J (1989). Zell und Gewebekultur. Jena, Berlin: GustavFischer-Verlag, pp. 181.
Mangalindan GC, Talaue MT, Cruz LJ, Franzblau SG, Adams LB, Richardson AD, Ireland CM, Concepcion GP (2000). Agelasine F from a Philippine Agelas sp. sponge exhibits in vitro antituberculosis activity. Planta Med., 66(4): 364-365.

Mativandlela SPN, Meyer JJM, Hussein AA, Houghton PJ, Hamilton CJ, Lall $N$ (2008). Activity against Mycobacterium smegmatis and $M$. tuberculosis by extract of South African medicinal plants. Phytother Res., 22(6): 841-845.

Mekhfi H, El Haouari M, Bnouham M, Aziz M, Ziyyat A, Legssyer A (2006). Effects of extracts and tannins from Arbutus unedo leaves on ratplatelet aggregation. Phytother. Res., 20: 135-139.

Mitscher LA, Baker WR (1998). A search for novel chemotherapy against tuberculosis amongst natural products. Pure Appl. Chem., 70(2): 365-371

Morissette C, Francoeur C, Darmond-Zwaig C, Gervais F (1996). Lung phagocyte bactericidal function in strains of mice resistant and susceptible to Pseudomonas aeruginosa. Infect. Immun., 64(12): 4984-4992.

Newton SM, Lau C, Wright C (2000). A review of antimycobaterial natural products. Phytother. Res., 14(5): 303-322.

Newton SM, Lau C, Gurcha SS, Besra GS, Wright CW (2002). The evaluation of forty-three plant species for in vitro antimycobacterial activities; isolation of active constituents from Psoralea corylifolia and Sanguinaria canadensis. J. Ethnopharmacol., 79(1): 57-67.

Okunade AL, Elvin-Lewis MPF, Lewis WH (2004). Natural antimycobacterial metabolites: current status. Phytochemistry, 65: 1017-1032.

Olila D, Olwa-Odyek, Opuda-Asibo J (2001). Antibacterial and antifungal activities of extracts of Zanthoxylum chalybeum and Warburgia ugandensis, Ugandan medicinal plants. Afr. Health Sci. 1(2): 66-72.

Pabuçcuoğlu A, Kıvçak B, Baş M, Mert T (2003). Antioxidant activity of Arbutus unedo leaves., Fitoterapia, 74: 597-599.

Papa F, Rivière M, Fournié JJ, Puzo G, David H (1987). Specificity of a Mycobacterium kansasii phenolic glycolipid (mycoside A) immunoserum. J. Clin. Microbiol., 25(12): 2270-2273.

Rastogi N, Pota MC, David HL (1987). Intracellular growth of pathogenic mycobacteria in the continuous murine macrophage cell line J-774: Ultrastructure and drug-susceptibility studies. Curr. Microbiol., 16(2): 79-92.

Rastogi N, Labrousse V, Goh KS, De Sousa JP (1991). Antimycobacterial spectrum of sparfloxacin and its activities alone and in association with other drugs against Mycobacterium avium complex growing extracellularly and intracellularly in murine and human macrophages. Antimicrob. Agents Chemother., 35(12): 2473-2480.

Rocha-Afonso ML (1991). Plantas do Algarve. Serviço Nacional de Parques, Recursos e Conservaçoã da Natureza, Lisboa. pp. 395

Seidemann J (1995). Zur Kenntnis von wenig bekannten exotischen FruK chten. 5. Mitt.: Baumerdbeere (Arbutus unedo L.). Dtsch. Lebensmittel-Rdsch. 91: 110-113.

Sharbati-Tehrani S, Stephan J, Holland G, Appel B, Niederweis M, Lewin A (2005). Porins limit the intracellular persistence of Mycobacterium smegmatis. Microbiology, 151(Pt7): 2403-2410.

Skinner PS, Furney SK, Kleinert DA, Orme IM (1995). Comparison of activities of fluoroquinolones in murine macrophages infected with Mycobacterium tuberculosis. Antimicrob. Agents Chemother., 39(3): 750-753.

Sosunov V, Mischenko V, Eruslanov B, Edward Svetoch E, Shakina Y, Stern N, Majorov K, Sorokoumova G, Selishcheva A, Apt A (2007). Antimycobacterial activity of bacteriocins and their complexes with liposomes. JAC, 59: 919-925.

World Health Organisation (2008). Global Tuberculosis Control: Surveillance, Planning and Financing. WHO, Geneva. www.sahealthinfo.org/noveldrug/novelpamphlet.htm (accessed 30 April 2008).

Zager EM, McNerney R (2008). Multidrug-resistant tuberculosis. Bio MedCentral Infectious Dis., 8: 10, doi:10.1186/1471-2334-8-10.

Zahrt TC (2003). Molecular mechanisms regulating persistent Mycobacterium tuberculosis infection. Microbes Infect. 5: 159-167.

Ziyyat A, Legssyer A, Mekhfi H, Dassouli A, Serhrouchni M, Benjelloun W (1997). Phytotherapy of hypertension and diabetes in oriental Morocco. J. Ethnopharmacol., 58: 45-54. 
Ziyyat A, Boussairi E (1998). Cardiovascular effects of Arbutus unedo $L$. in spontaneously hypertensive rats. Phytother Res., 12: 110-113.

Ziyyat A, Mekhfi $\mathrm{H}$, Bnouham M, Tahri A, Legssyer A, Hoerter J, Fischmeister R (2002). Arbutus unedo induces endotheliumdependent relaxation of the isolated rat aorta. Phytotherapy Res., 16: 572-575. 